\title{
TÉCNICAS DE GEOPROCESSAMENTO PARA DELIMITAÇÃO DE SISTEMAS FÍSICO-NATURAIS E AÇÕES DE PLANEJAMENTO: O CASO DO MUNICÍPIO DE IPU - CE
}

\author{
Ana Larissa Ribeiro de Freitas ${ }^{(a)}$, Francisco Davy Braz Rabelo ${ }^{(b)}$, Edson Vicente da Silva $^{(\mathrm{c})}$, \\ Ernane Cortez Lima ${ }^{(\mathrm{d})}$ \\ (a) Departamento de Geografia, Universidade Federal do Ceará - UFC, Email: alarisig@ gmail.com \\ (b) Departamento de Geografia, Universidade Federal do Ceará - UFC, Email: davyrabelo@ yahoo.com.br \\ (c) Departamento de Geografia, Universidade Federal do Ceará - UFC, Email: cacauceara@ gmail.com \\ (d) Departamento de Geografia, Universidade Estadual Vale do Acaraú - UVA, Email: ernanecortez@ hotmail.com
}

\section{EIXO: GEOTECNOLOGIAS E MODELAGEM ESPACIAL EM GEOGRAFIA FÍSICA}

\begin{abstract}
Resumo
O trabalho foi desenvolvido como forma de subsidiar ações de planejamento e gestão ambiental no município de Ipu-Ce, a partir de uma metodologia geoecológica fundamentada na análise integrada da relação natureza-sociedade a partir de uma caracterização socioeconômica e natural. Foram elaborados mapas através do uso de geotecnologias de informações geográficas, de forma a delimitar os sistemas físico-naturais, possibilitando a caracterização e discussão do mesmo. Percebe-se, em Rodriguez (1994), que os sistemas formadores da paisagem são complexos e exigem uma multiplicidade de classificações que podem, segundo o autor, enquadrar-se perfeitamente em três princípios básicos de análise: o genético, o estrutural sistêmico e o histórico, que se fundem numa classificação complexa. Conhecer esses sistemas físico-naturais e sua relação com a sociedade é importante para tomadas de decisões territoriais, pautadas na capacidade de suporte dos mesmos com relação à atividade antrópica.
\end{abstract}

Palavras chave: Planejamento Ambiental; Gestão Ambiental; Geotecnologias.

\section{Introdução}

O Ceará tem a maior parte do território inserido no clima semiárido, marcado pela irregularidade e incerteza do regime de chuvas apresentando uma vulnerabilidade tanto social como ambiental, necessitando assim de estudos que possibilitem uma visão socioambiental e que amortizem a degradação dos recursos naturais. A aplicação da metodologia geoecológica traz uma aproximação entre os aspectos físicos naturais com aspectos sociais e econômicos tendo em vista o planejamento territorial.

O trabalho foi desenvolvido no município de Ipu, onde estudos existentes apontam formas inadequadas de apropriação da natureza, como desvios e poluição de cursos d'água pela atividade agrícola além de extrativismo vegetal e mineral, figurando entre os principais problemas enfrentados. Para isso os sistemas físico-naturais foram delimitados cartograficamente e relacionados em forma de quadro para facilitar a sua visualização e discussão. 
XVII Simpósio Brasileiro de Geografia Fisica Aplicada

I Congresso Nacional de Geografia Física
OS DESAFIOS DA GEOGRAFIA FÍSICA NA FRONTEIRA DO CONHECIMENTO

Instituto de Geociências - Unicamp

Campinas - SP

28 de Junho à 02 de Julho de 2017

Em Lima e Silva (2015) a análise das potencialidades e riscos próprios à utilização dos recursos naturais para o desenvolvimento apropriado é parte do planejar um determinado ambiente, e através do planejamento a localidade é percebida conforme seu potencial de uso, levando em conta a questão ambiental. Observa-se assim a importância de compreender e delimitar estes sistemas físico-naturais.

A área trabalhada foi o município de Ipu (figura 01), situado no noroeste do estado do Ceará, localizado na Mesorregião do Noroeste Cearense e na Microrregião de Ipu (IPECE, 2015). O município faz parte da área de influência do Parque Nacional de Ubajara (ICMBio, 2017), criado em 30 de abril de 1959 através do Decreto Federal $n^{\circ}$ 45.954/59, que atrelada a necessidade de proteger e conservar o Riacho Ipuçaba, inserido no Planalto Sedimentar da Ibiapaba e na depressão sertaneja. Outra unidade existente é a APA da Bica do Ipu, pelo decreto municipal $\mathrm{n}^{\circ} 25.354$, de 26 de janeiro de 1999, criando assim um corredor ecológico na encosta da Serra da Ibiapaba.

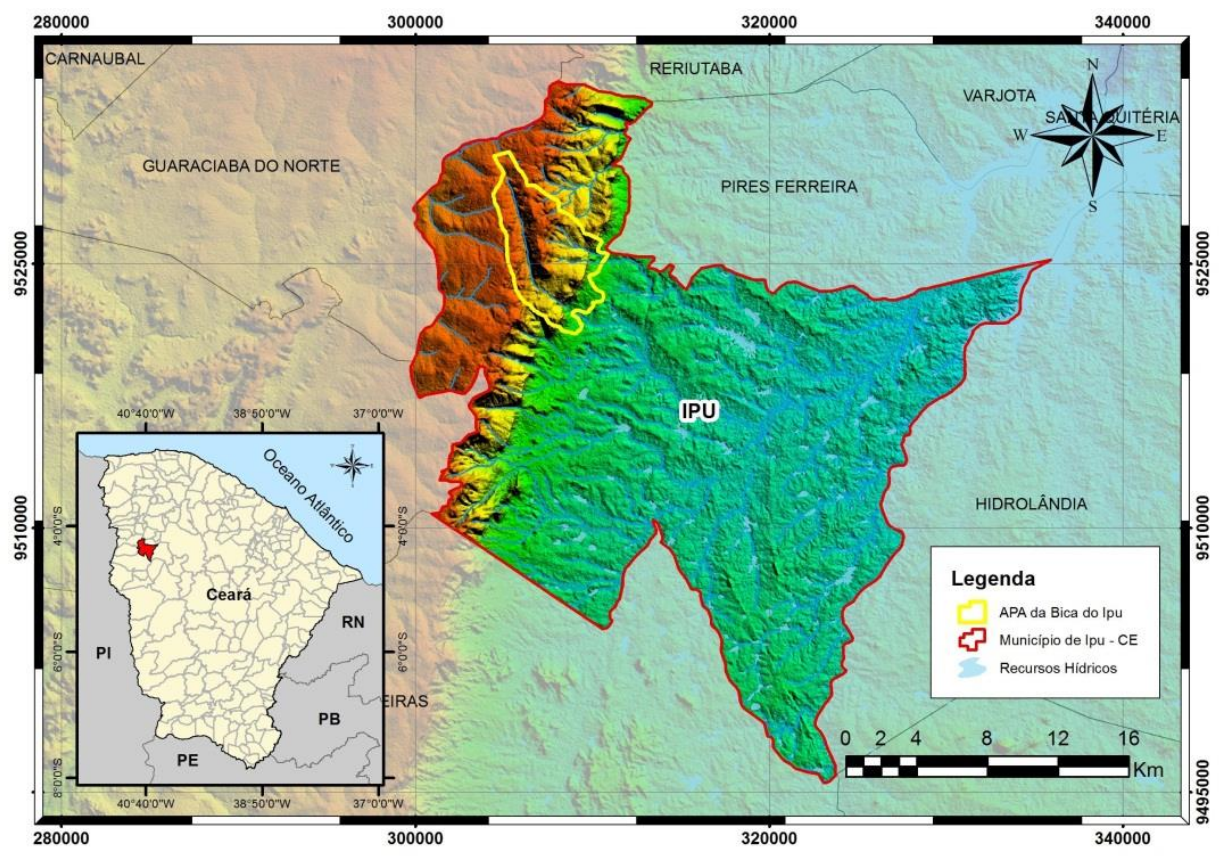

Figura 01: mapa de localização do município de Ipu, Ceará.

No dia 26 de abril de 1973, foi assinado o Decreto $\mathrm{n}^{\circ} 72.144$, alterando os seus limites para uma área de 563 hectares. No dia 13 de dezembro de 2002, foi assinado o Decreto Sem Número e publicado no Diário Oficial da União, que altera, mais uma vez, os limites do Parque Nacional para uma área de 6.288 hectares, passando, assim, a abranger os municípios de Ubajara, Tianguá e Frecheirinha (ICMbio, 2017).

\section{Material e métodos}


O conceito de sistemas foi proposto enquanto teoria por Ludwig von Bertalanffy, que considera o mesmo como um conjunto de partes interagentes e interdependentes que, conjuntamente, formam um todo unitário com determinado objetivo e efetuam determinada função (BERTALANFFY, 1975). A partir da Teoria Geral dos Sistemas - TGS diversas áreas do conhecimento trabalharam nas variações dessa abordagem, aplicando os fundamentos da TGS em uma ampla gama de estudos.

No campo da Geografia diversas vertentes foram derivadas, na perspectiva geossistêmica (Sotchava, 1977, 1978; Bertrand, 1972, 2007) e geocológica (Carl Troll, 1939/ Rodriguez e Silva, 2002; Rodriguez et al. 2004;), onde unidades do espaço geográfico, como os sistemas ambientais constituem áreas a serem objetos de planejamento, junto com seus possíveis sub-sistemas, como no caso dos ambientes semiáridos com distintas feições geoecológicas, onde a compartimentação dos mesmo estrutura-se como ferramenta fundamental dos estudos ambientais.

Rodriguez e Silva (2002) consideram o critério de homogeneidade (tipologia) das condições naturais uma das categorias de sistematização das paisagens naturais, onde a análise geoecológica da paisagem busca distinguir as unidades pela sua semelhança e repetição contribuindo na geração de diferentes valores e utilidades para o planejamento e a gestão ambiental.

Para delimitação cartográfica dos sistemas ambientais foram adquiridos os dados de 1 arco segundo (1") da Shuttle Radar Topography Mission - SRTM, atualmente com a resolução de 30 metros, em conjunto com as imagens do programa Landsat 8, com resolução espacial de 30 metros (bandas multiespectrais) e 15 metros na Pancromática, ambos disponibilizados na plataforma EarthExplorer, do United States Geological Survey - USGS. O mapeamento dos sistemas físico-naturais do município do Ipu foi realizado a partir da interpretação das imagens de satélite e geração curvas de nível com equidistâncias de 30 metros, pela interpretação da variação da hipsométrica. Para validar as informações geradas foram realizados trabalhos de campo, onde foi realizado o reconhecimento da verdade terrestre para adequar o esboço cartográfico construído a partir da interpretação preliminar das imagens SRTM e Landsat 8, além de verificar as formas de uso e ocupação das respetivas unidades.

\section{Resultados e discussões}

O trabalho traz como resultado um diagnóstico do meio físico atreatreladolado aos impactos das atividades antrópicas por meio do mapeamento dos sistemas ambientais do município de Ipu - CE (figura 02), com base em imagens orbitais do satélite landsat 8 e da missão SRTM, com elaboração de um quadro síntese de caracterização desses sistemas, com especificações de potencialidade e limitações, explicando a capacidade produtiva. 


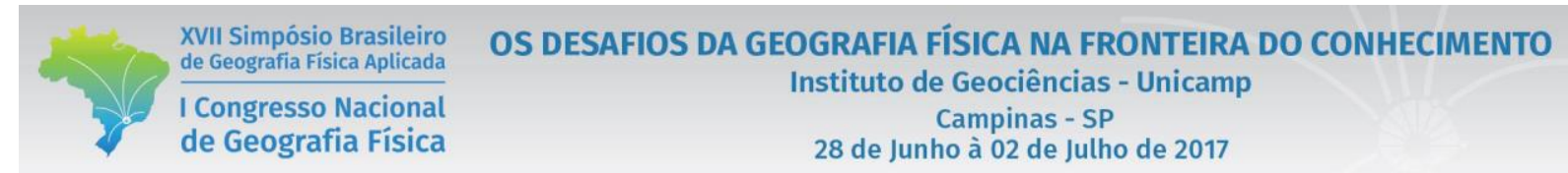

Para explicar a capacidade produtiva é importante compreender a dinâmica natural que o município está inserido (quadro 01). Dessa forma podem-se observar na depressão sertaneja atividades ligadas ao extrativismo vegetal e mineral, como extração de lenha para manutenção de cercas, abastecimento das olarias, juntamente à extração de argila e de água. Além da prática de queimadas para "limpar" o solo. As atividades nas olarias prejudicam ainda a planície fluvial, devido ao desmatamento e poluição das águas, vale observar que em alguns pontos não eram respeitados os limites da APP.

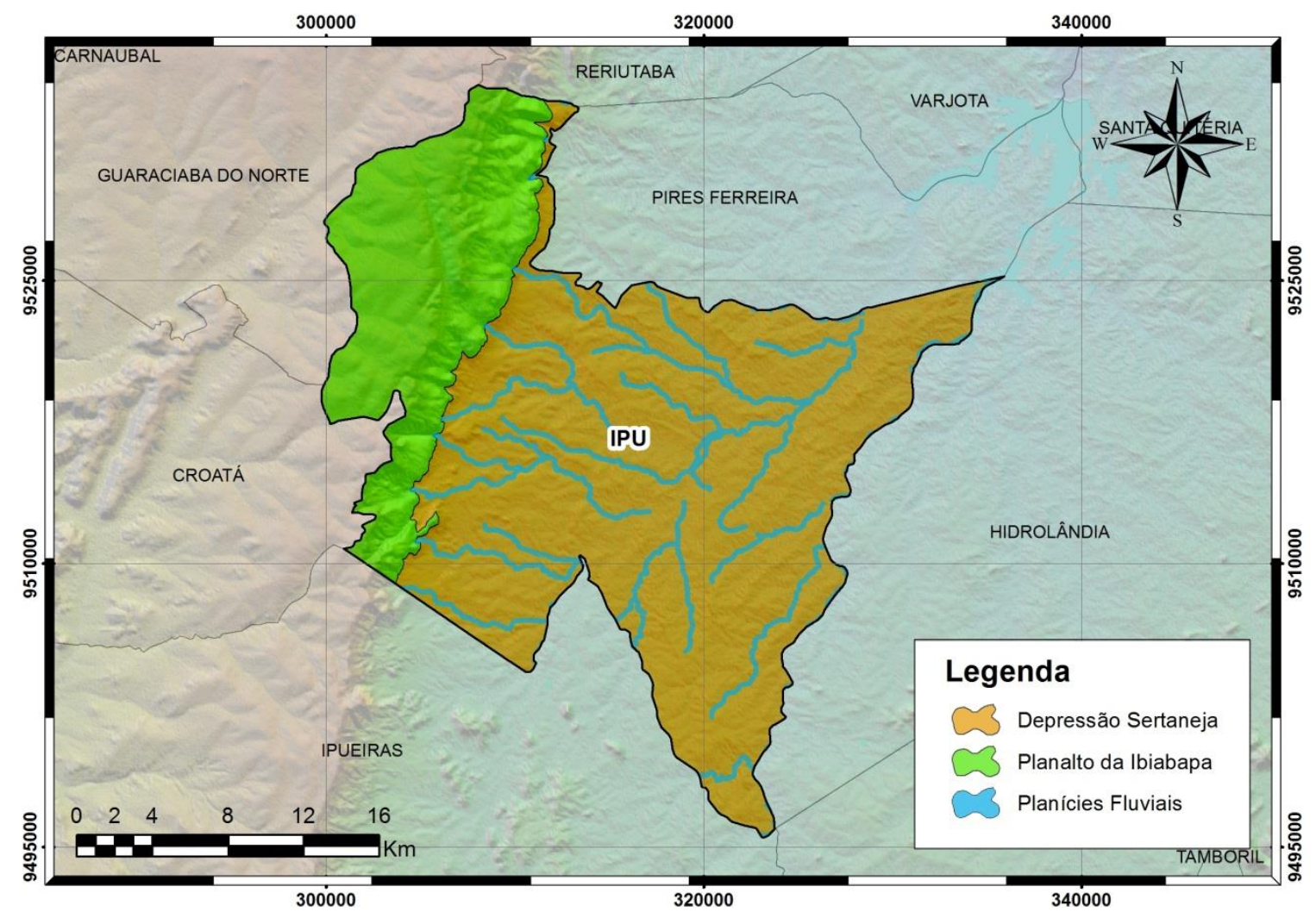

Figura 02: Sistemas Ambientais do município de Ipu, Ceará.

Quadro 01: Caracterização dos Sistemas Físico-Naturais.

\begin{tabular}{|c|c|c|c|}
\hline $\begin{array}{c}\text { Sistemas } \\
\text { Ambientais }\end{array}$ & Caracterização & Potencialidades & Limitações \\
\hline $\begin{array}{l}\text { Depressão } \\
\text { Sertaneja }\end{array}$ & $\begin{array}{l}\text { Abrange a maior parte da área do município, é um ambiente de transição } \\
\text { estável e vulnerabilidade moderada, possui embasamento cristalino com } \\
\text { superfície aplainada conservada e moderadamente dissecada, com altitude } \\
\text { entre } 170-290 \mathrm{~m} \text {; clima semiárido quente, com intensidade pluviométrica nos } \\
\text { meses de janeiro-maio entre } 700-900 \mathrm{~mm} \text { anuais, influenciando num fluxo } \\
\text { hídrico sazonal devido ao baixo potencial de águas subterrâneas; presença de } \\
\text { luvissolos com fertilidade média a alta, planossolo de baixa fertilidade e } \\
\text { neossoloflúvico de boa fertilidade; presença de afloramentos rochosos; } \\
\text { revestimento vegetal de caatinga arbustivo-arbóreas e matas ciliares. (Souza, } \\
2000 \text { ) }\end{array}$ & $\begin{array}{l}\text { Relevo sem muitos } \\
\text { deslizamentos de } \\
\text { encostas; Pecuária } \\
\text { extensiva; Atividade } \\
\text { agrícola; Extrativismo } \\
\text { vegetal e mineral; } \\
\text { Variedade litológica; } \\
\text { Rochas ornamentais; } \\
\text { Drenagem superficial } \\
\text { densa; Açudagem. }\end{array}$ & $\begin{array}{l}\text { Mecanização do solo; } \\
\text { Salinização do solo; } \\
\text { Irregularidade hídrica; } \\
\text { Suscetibilidade à } \\
\text { queimada; Vegetação com } \\
\text { baixa capacidade de } \\
\text { proteção do solo; } \\
\text { Processos erosivos; Baixa } \\
\text { sustentabilidade. }\end{array}$ \\
\hline $\begin{array}{l}\text { Planalto } \\
\text { Sedimentar }\end{array}$ & $\begin{array}{l}\text { Superfície elevada em torno dos } 900 \mathrm{~m} \text { de altitude; revestida por arenitos em } \\
\text { estrutura dissimétrica com vertente escarpada para leste e reverso com declives } \\
\text { suaves em direção à cidade, com vulnerabilidade à erosão; clima úmido e } \\
\text { subumido com precipitação anual chegando aos } 1.400 \mathrm{~mm} \text {; padrão de drenagem } \\
\text { em paralelo; solos espessos, ácidos e com fertilidade baixa. (Souza, 2000) }\end{array}$ & $\begin{array}{l}\text { Solos profundos; } \\
\text { Altosíndices } \\
\text { pluviométricos anuais; } \\
\text { Águas subsuperficiais; } \\
\text { Agricultura. }\end{array}$ & $\begin{array}{l}\text { Acidez e fertilidade baixa } \\
\text { nos solos; Declividade } \\
\quad \text { acentuada e } \\
\text { desmatamento nas } \\
\text { vertentes; baixo potencial } \\
\text { de águas superficiais. }\end{array}$ \\
\hline
\end{tabular}




\begin{tabular}{|c|c|c|c|}
\hline $\begin{array}{l}\text { Planície } \\
\text { Fluvial }\end{array}$ & $\begin{array}{l}\text { São áreas planas resultantes da acumulação fluvial e sujeitas a inundações } \\
\text { periódicas que bordejam as calhas dos rios, e se alargando nos baixos vales; } \\
\text { devido ao regime intermitente dos rios, a planície fluvial ocupa uma pequena } \\
\text { área, sendo revertida por matas ciliares, um destaque para a presença de } \\
\text { carnaúbas - Coperniciaprunifera -, neossoloflúvico. (Souza, 2000) }\end{array}$ & $\begin{array}{l}\text { Solos profundos; } \\
\text { Extrativismo mineral; } \\
\text { Presença hídrica; } \\
\text { Projetos de irrigação; } \\
\text { Agropecuária. }\end{array}$ & $\begin{array}{l}\text { Área de Proteção } \\
\text { Permanente; Possibilidade } \\
\text { de salinização; Problemas } \\
\text { em áreas urbanas durante } \\
\text { o período chuvoso. }\end{array}$ \\
\hline
\end{tabular}

No entanto, um dos maiores problemas observados se dá no planalto sedimentar, onde desvios e represamentos são realizados ao longo do Riacho Ipuçaba, que é protegido pela APA da Bica do Ipu, tais atividades estão em constantes discussões do conselho gestor, onde um trabalho estratégico de planejamento com foco na educação ambiental vem sendo desenvolvido.

Os resultados aqui obtidos buscam subsidiar informações a pesquisas que venham a ser desenvolvidos no município, que embora esteja inserido dentro de importantes conjuntos de sistemas físico-naturais, como o Planalto da Ibiapaba, a Depressão Periférica da Ibiapaba e os Sertões do Acaraú e do Coreaú (Souza 2000), não é foco de estudos científicos de modo geral.

\section{Conclusão}

Foi possível concluir que a delimitação de sistemas ambientais pode ser realizada tendo como apoio os produtos SRTM e imagens de satélite, otimizando-se o processo de definição dos grandes sistemas por meio da variação altimétrica do terreno e interpretação de imagens, atrelados ao trabalho de campo, possibilitando a realizar a definição das potencialidades, limitações e problemas encontrados em cada uma dos respectivos sistemas.

\section{Bibliografia}

BERTALANFFY, Ludwig von. Teoria Geral dos Sistemas: fundamentos, desenvolvimento e aplicação. Petrópolis-RJ: Vozes,. 1975.BERTRAND, Georges. Paisagem e Geografia Física Global - esboço metodológico. Caderno de Ciências da Terra. São Paulo, SP: Instituto de Geografia - USP, 1972.

BERTRAND, G.; BERTRAND, C. Uma Geografia transversal e de travessias: o meio ambiente através dos territórios e das temporalidades. Organizador Messias Modesto Passos. Maringá, PR: Ed. Massoni, 2007.

ICMBIO. Plano de Manejo: Encarte 4- Contexto Regional. Disponível em: <http://www.icmbio.gov.br/parnaubajara/planos-de-manejo>. Acesso em: 10 mar. 2017.

LIMA, E. C.; SILVA, E. V. ESTUdOS GEOSSISTÊMICOS APLICADOS À BACIAS HIDROGRÁFICAS. Revista Equador, Piauí, v. 4, n. 4, p.3-20, dez/2015.

RODRIGUEZ J., SILVA E.V. A classificação das paisagens a partir de uma visão geossistêmica. Mercator, Revista do Depto. de Geografia-UFC. 1(1): 98-115, 2002.

RODRIGUEZ, J. M.; SILVA, E. V. DA; CAVALCANTI, A. P. B. Geoecologia das Paisagens: uma visão geossistêmica da análise ambiental. Fortaleza: Edições UFC, 2004. 


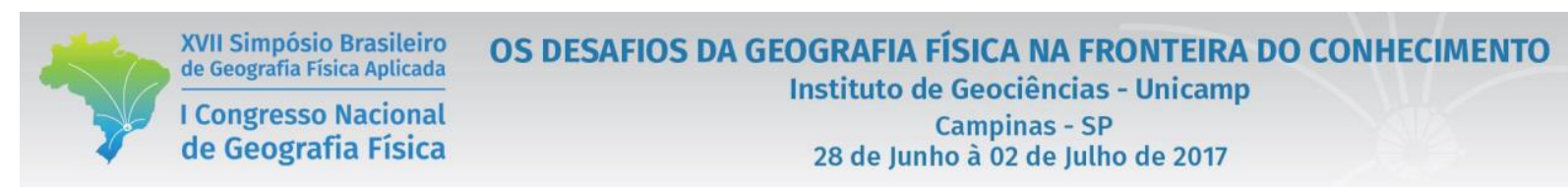

SOTCHAVA, V. B. O estudo de geossistemas. São Paulo: Instituto de Geografia USP, 1977.

SOTCHAVA, V. B. Por uma teoria de classificação de geossistemas da vida terrestre. São Paulo: Instituto de Geografia USP, 1978.

SOUZA, M. J. N. Bases Naturais e Esboço do Zoneamento Geoambiental do Estado do Ceará. In: LIMA, L. C; SOUZA, M. J. N; MORAES, J. O. Compartimentação territorial e gestão regional do Ceará. Editora FUNECE: Fortaleza, 2000 